\title{
Ultrasound guided interstitial photodynamic therapy of deep seated
} lesions

\author{
Sorcha MacKay, Waseem Jerjes, Tahwinder Upile, Syedda Abbas, \\ Zaid Hamdoon, Farai Nhembe, Shinali Patel, Priya Shah, \\ Michael Vourvachis, Simon Morley and Colin Hopper*
}

Address: Head \& Neck Centre, University College London Hospitals, London, UK

* Corresponding author

from Ist Scientific Meeting of the Head and Neck Optical Diagnostics Society

London, UK. I 4 March 2009

Published: 28 July 2009

Head \& Neck Oncology 2009, I(SuppI I):PI0 doi:I0.I I86/I758-3284-I-SI-PI0

This abstract is available from: http://www.headandneckoncology.org/content/I/SI/PIO

(c) 2009 MacKay et al; licensee BioMed Central Ltd.

\section{Introduction}

Photodynamic therapy is a minimally invasive therapy that results from the interaction between a photosensitiser, oxygen and light. The delivery of light can by either by surface illumination or interstitial application.

We describe the intraoperative application of ultrasound in guiding light delivery in photodynamic therapy.

\section{Materials and methods}

A total of 60 patients with various deep seated pathologies in the head \& neck, upper and lower limbs were treated with mTHPC-photodynamic therapy. 2D Ultrasound was used to guide the needle insertion in the diseased area.

\section{Results}

It was possible to clearly identify the needles during insertion in all treatments and it was possible to guide parallel needle insertions using ultrasound. Although the resolution of ultrasound is not as good as other imaging modalities (i.e. CT, MRI) it was satisfactory in identifying the centre and the peripheries of the pathological lesions.

Ultrasound is very easy to perform, non-invasive, relatively inexpensive, quick and convenient, suited to imaging soft tissues and does not cause any discomfort.

\section{Conclusion}

Ultrasound can be used to guide 'real-time' photodynamic therapy of deep seated tumours and other malformations and can augment the information from other imaging modalities without affecting the patient's treatment outcome. 